\title{
Fracture Risk and Zoledronic Acid Therapy in Men with Osteoporosis
}

\author{
Steven Boonen, M.D., Ph.D., Jean-Yves Reginster, M.D., Ph.D., \\ Jean-Marc Kaufman, M.D., Ph.D., Kurt Lippuner, M.D., Jose Zanchetta, M.D., \\ Bente Langdahl, Ph.D., D.M.Sc., Rene Rizzoli, M.D., Stanley Lipschitz, M.B., B.Ch., \\ Hans Peter Dimai, M.D., Richard Witvrouw, M.D., Erik Eriksen, M.D., D.M.Sc., \\ Kim Brixen, M.D., Ph.D., Luis Russo, M.D., Ph.D., Frank Claessens, Ph.D., \\ Philemon Papanastasiou, Ph.D., Oscar Antunez, M.D., Guoqin Su, Ph.D., \\ Christina Bucci-Rechtweg, M.D., Josef Hruska, M.D., Elodie Incera, M.S., \\ Dirk Vanderschueren, M.D., Ph.D., and Eric Orwoll, M.D.
}

From the Katholieke Universiteit Leuven, Leuven (S.B., F.C., D.V.), University of Liege, Liege (J.-Y.R.), Ghent University, Ghent (J.-M.K.), and Ziekenhuis OostLimburg, Genk (R.W.) - all in Belgium; University of Bern, Bern (K.L.), Rehabilitation and Geriatrics, Geneva University Hospitals, Geneva (R.R.), and Novartis Pharma, Basel (P.P., J.H., E.I.) - all in Switzerland; Universidad del Salvador, Buenos Aires (J.Z.); Aarhus University Hospital, Aarhus (B.L.), and University of Southern Denmark, Odense (K.B.) - both in Denmark; Bone Mineral Density Clinic, Johannesburg (S.L.); Medical University of Graz, Graz, Austria (H.P.D.); University of Oslo, Oslo (E.E.); Brazil Center for Clinic and Basic Research, Rio de Janeiro (L.R.); Novartis Pharmaceuticals, East Hanover, NJ (O.A., G.S., C.B.-R.); and Oregon Health and Science University, Portland (E.O.). Address reprint requests to Dr. Boonen at the Center for Metabolic Bone Diseases and Division of Geriatric Medicine, University Hospitals Leuven, Herestraat 49, B-3000 Leuven, Belgium, or at steven.boonen@uz.kuleuven.ac.be.

N Engl J Med 2012;367:1714-23.

DOI: 10.1056/NEJMoa1204061

Copyright @ 2012 Massachusetts Medical Society.
ABSTRACT

\section{BACKGROUND}

Fractures in men are a major health issue, and data on the antifracture efficacy of therapies for osteoporosis in men are limited. We studied the effect of zoledronic acid on fracture risk among men with osteoporosis.

\section{METHODS}

In this multicenter, double-blind, placebo-controlled trial, we randomly assigned 1199 men with primary or hypogonadism-associated osteoporosis who were 50 to 85 years of age to receive an intravenous infusion of zoledronic acid $(5 \mathrm{mg})$ or placebo at baseline and at 12 months. Participants received daily calcium and vitamin D supplementation. The primary end point was the proportion of participants with one or more new morphometric vertebral fractures over a period of 24 months.

\section{RESULTS}

The rate of any new morphometric vertebral fracture was $1.6 \%$ in the zoledronic acid group and $4.9 \%$ in the placebo group over the 24-month period, representing a $67 \%$ risk reduction with zoledronic acid (relative risk, 0.33 ; 95\% confidence interval, 0.16 to $0.70 ; \mathrm{P}=0.002$ ). As compared with men who received placebo, men who received zoledronic acid had fewer moderate-to-severe vertebral fractures $(\mathrm{P}=0.03)$ and less height loss $(\mathrm{P}=0.002)$. Fewer participants who received zoledronic acid had clinical vertebral or nonvertebral fractures, although this difference did not reach significance because of the small number of fractures. Bone mineral density was higher and bone-turnover markers were lower in the men who received zoledronic acid ( $\mathrm{P}<0.05$ for both comparisons). Results were similar in men with low serum levels of total testosterone. The zoledronic acid and placebo groups did not differ significantly with respect to the incidence of death (2.6\% and $2.9 \%$, respectively) or serious adverse events (25.3\% and $25.2 \%$ ).

\section{CONCLUSIONS}

Zoledronic acid treatment was associated with a significantly reduced risk of vertebral fracture among men with osteoporosis. (Funded by Novartis Pharma; ClinicalTrials .gov number, NCT00439647.) 
STEOPOROSIS IS AN IMPORTANT CAUSE of morbidity and mortality among men., ${ }^{1,2}$ Among persons older than 50 years of age, approximately $40 \%$ of all osteoporotic fractures worldwide occur in men. ${ }^{3}$ Mortality after osteoporotic fracture is higher among men than among women. ${ }^{2,4}$

Previous studies involving men with osteoporosis have focused on the surrogate outcomes of bone mineral density and bone-turnover markers, ${ }^{5-9}$ but data from double-blind, randomized studies assessing antifracture efficacy are lacking. In addition, given the low awareness of the disease, ${ }^{10}$ the development of guidelines for the detection and treatment of osteoporosis in men has been limited. ${ }^{11}$ Hence, there is a need for randomized trials of osteoporosis treatment in men, with fracture as a primary end point. Men at risk for fractures are commonly not identified or treated. ${ }^{12}$

Zoledronic acid (Reclast, Novartis Pharmaceuticals; Aclasta, Novartis Pharma) is a bisphosphonate administered intravenously. At a dose of $5 \mathrm{mg}$ once a year, it has antifracture efficacy in postmenopausal women with osteoporosis and positive effects on bone mineral density in men. ${ }^{13,14}$ Our multicenter, randomized, prospective trial assessed the effect of zoledronic acid on the risk of vertebral fracture among men with osteoporosis.

\section{METHODS}

\section{PARTICIPANTS}

Men 50 to 85 years of age who had primary osteoporosis or osteoporosis associated with low testosterone levels were eligible to participate if they had a bone mineral density $\mathrm{T}$ score of -1.5 or less (based on the device-specific reference values for men) at the total hip or femoral neck and one to three prevalent vertebral fractures of mild or moderate grade, as assessed by means of the modified semiquantitative method developed by Genant et al. ${ }^{15}$ Men without fractures were eligible if they had a bone mineral density $\mathrm{T}$ score of -2.5 or less at the total hip, femoral neck, or lumbar spine.

Exclusion criteria included four or more prevalent vertebral fractures; a 25-hydroxyvitamin D level of less than $15 \mathrm{ng}$ per milliliter (37.4 nmol per liter) during screening; baseline renal insufficiency (calculated creatinine clearance, $<30.0 \mathrm{ml}$ per minute) ${ }^{16}$; a serum alkaline phosphatase level greater than 1.5 times the upper limit of the normal range or an aspartate aminotransferase or alanine aminotransferase level greater than 3 times the upper limit of the normal range; hypercalcemia or hypocalcemia; hypersensitivity to bisphosphonates; and treatment with strontium ranelate or sodium fluoride. Patients who were receiving treatment with oral or intravenous bisphosphonates, teriparatide, calcitonin, or oral or intravenous glucocorticoids were eligible if the prespecified washout criteria were met before randomization. For oral bisphosphonates, the washout period was 2 years (if used for $\geq 48$ weeks), 1 year (if used for $>8$ but $<48$ weeks), or 6 months (if used for $>2$ but $\leq 8$ weeks); for intravenous bisphosphonates, the washout period was 2 years. For teriparatide or other parathyroid hormone therapies, the washout period was 3 months (if used for $\leq 1$ week). For calcitonin, the washout period was 6 months (if used for $\geq 12$ weeks) or 3 months (if used for $\geq 4$ but $<12$ weeks). For oral or intravenous glucocorticoids, the washout period was 1 year. Additional exclusion criteria included the use of testosterone within 1 year before randomization, the use of anabolic steroids or growth hormone within 6 months before randomization, and treatment with any investigational drug or drugs, devices, or both within 30 days before randomization; bilateral hip replacement; and active hyperthyroidism, primary hyperparathyroidism, or hypoparathyroidism. Use of oral bisphosphonates, parathyroid hormone, sodium fluoride, strontium ranelate, calcitonin, testosterone, systemic glucocorticoids or anabolic steroids, and any investigational therapy except the study medication were prohibited throughout the trial.

\section{STUDY DESIGN}

This 24-month, randomized, double-blind, placebo-controlled, parallel-group study was conducted in Europe, South America, Africa, and Australia from December 2006 to October 2010. Between January 2007 and September 2008, participants were randomly assigned in a 1:1 ratio to receive zoledronic acid at a dose of $5 \mathrm{mg}$ or placebo, administered as a 15- to 30-minute intravenous infusion at baseline and month 12 . Randomization was stratified according to study center and was performed with the use of a computer-generated randomization list. All men received daily calcium at a dose of 1000 to $1500 \mathrm{mg}$ (in single or divided doses at the investigator's discretion) and vitamin D at a dose of 800 to 1200 IU. All 
study participants and researchers were unaware of the study-drug assignments throughout the trial.

The study was designed and implemented in accordance with the Harmonized Tripartite Guideline for Good Clinical Practice from the International Conference on Harmonization and the Declaration of Helsinki, ${ }^{17}$ with applicable local regulations. The institutional review board at each center approved the protocol, and all participants provided written informed consent. An external data monitoring committee periodically reviewed the safety information throughout the study (details are available in the Supplementary Appendix, available with the full text of this article at NEJM .org). The study protocol is available at NEJM.org.

The study was designed by representatives of the sponsor, Novartis Pharma, in cooperation with the first author. Data were analyzed by biostatisticians at PPD UK, who were paid by the sponsor, and by representatives of the sponsor. The data were reanalyzed and the results were confirmed by an independent statistical consultant. The first and last authors wrote the first draft of the manuscript and made the decision to submit the manuscript for publication. All authors had access to the study data and the clinical study report and assume responsibility for the completeness and accuracy of the reported data as well as the fidelity of the study to the study protocol. Editorial assistance was provided by an employee of BioScience Communications who was paid by Novartis.

\section{STUDY MEASUREMENTS}

Vertebral fractures were assessed by means of quantitative vertebral morphometry performed on lateral thoracic and lumbar-spine radiographs obtained at baseline and months 12 and 24. An incident vertebral fracture was assessed by means of morphometry and defined as a reduction in vertebral height of $20 \%$ or more and $4 \mathrm{~mm}$ or more. Body height was measured with the use of a stadiometer at screening and months 12 and 24. Clinical fractures (vertebral and nonvertebral) were reported by participants at each visit and were verified centrally by means of a radiographic report or surgical notes. Only confirmed fractures were included in the analysis of time to first clinical fracture. Bone mineral density and bone-turnover markers were analyzed in a subgroup of 100 or more participants. Bone mineral density at the lumbar spine, total hip, and femoral neck was assessed by means of dual-energy $\mathrm{x}$-ray absorpti- ometry at baseline and months 6,12 , and 24 . Boneturnover markers (fasting serum $\beta$-C-terminal telopeptide of type 1 collagen [ $\beta$-CTX], bonespecific alkaline phosphatase [BSAP], and procollagen type I N-terminal propeptide [PINP]) levels were measured at baseline and months 3, 6, $12,15,18$, and 24 . The serum level of total testosterone was measured once by means of radioimmunoassay at baseline.

Adverse events were recorded and coded with the use of the Medical Dictionary for Regulatory Activities system. Events meeting criteria for a maxillofacial adverse event or for cardiac arrhythmia classified as a serious adverse event were adjudicated by a committee of independent external experts who were unaware of the group assignments. Yearly assessments included laboratory tests (hematologic and chemical measurements and urinalysis), vital signs, body weight, and physical examination, with additional visits for renal monitoring 9 to 11 days and 90 days after each study-drug administration.

\section{STATISTICAL ANALYSIS}

The primary end point was the proportion of men with one or more new morphometric vertebral fractures over 24 months. Secondary end points were the proportion of men with one or more new morphometric vertebral fractures over 12 months; one or more new moderate-to-severe, or new or worsening morphometric vertebral fractures over 12 and 24 months; a change in height at months 12 and 24; the time to first clinical fracture (vertebral or nonvertebral); and changes from baseline in bone mineral density at the lumbar spine, total hip, and femoral neck and in bone-turnover markers. Overall safety was also assessed as a secondary objective.

Primary efficacy results were analyzed in the modified intention-to-treat population (participants who underwent baseline and one or more post-baseline assessments of the primary efficacy variable). For morphometric vertebral fractures, between-group differences were evaluated with the use of a logistic-regression model, with study group, number of baseline vertebral fractures $(0$, 1 , or $\geq 2$ ), and geographic region as explanatory variables. P values were calculated with a likelihood-ratio test. Relative risks and $95 \%$ confidence intervals were calculated by means of the twoby-two table method with the use of log-normal approximation. Binary variables were used for 


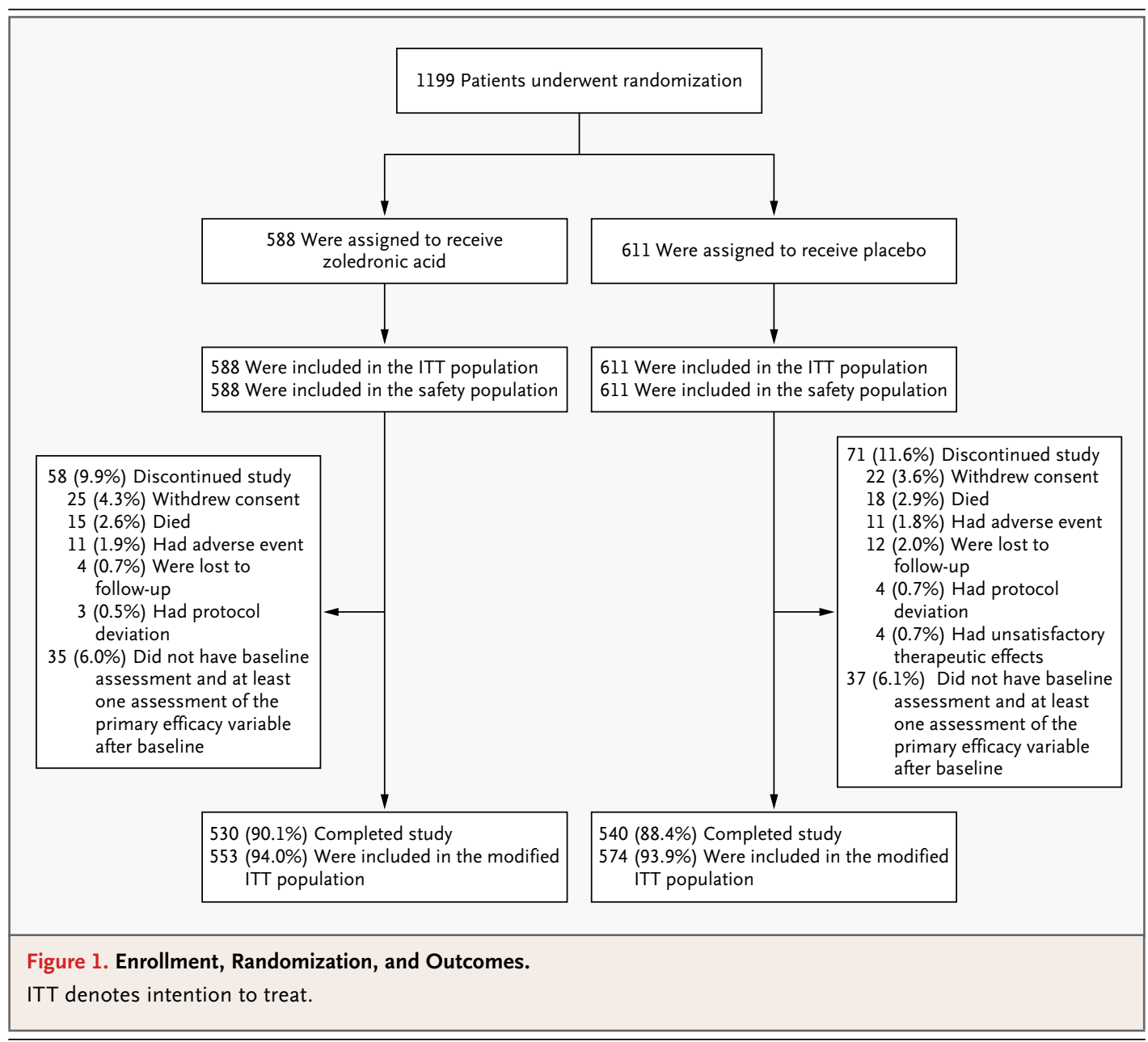

morphometric vertebral fracture, and in the case of missing data on fracture status at 24 months, the data were imputed with the use of the lastobservation-carried-forward method. If a month 12 radiograph was missing and the month 24 radiograph showed no fracture, it was assumed there was no fracture at month 12 . Clinical fracture was analyzed with the use of the Cox proportional-hazards method in the intention-totreat population. Bayesian analyses were also performed for clinical and nonvertebral fractures on the basis of data from the Health Outcomes and Reduced Incidence with Zoledronic Acid Once Yearly (HORIZON) Pivotal Fracture Trial ${ }^{13}$ and the HORIZON Recurrent Fracture Trial. ${ }^{14}$ Log hazard ratios from each study were combined with the use of the inverse-variance meta-analysis method. The meta-analysis mean was used as the prior mean. The prior variance was the meta-analysis mean variance plus a between-trial variance to discount the historical data. ${ }^{18}$ The $95 \%$ credible interval was based on the equal-tail method.

Changes in bone mineral density were analyzed with the use of an analysis of covariance (ANCOVA) model with treatment and baseline values as explanatory variables. Changes in height were compared with the use of an ANCOVA model with treatment, geographic region, and baseline values as explanatory variables. Changes in boneturnover markers were compared with the use of an ANCOVA model based on the log ratio of the post-baseline value to the baseline value, with treatment and log baseline values as explanatory variables. Within-group analyses of changes from baseline in bone-turnover markers were based on the least-squares means. The unadjusted mean percentage change was plotted over time for each bone-turnover marker.

Subgroup analyses of the fracture, bone mineral density, and bone-turnover marker end points 
Table 1. Baseline Characteristics of the Patients in the Intention-to-Treat Population.*

\begin{tabular}{|c|c|c|}
\hline Variable & $\begin{array}{l}\text { Zoledronic Acid } \\
\qquad(\mathrm{N}=588)\end{array}$ & $\begin{array}{l}\text { Placebo } \\
(\mathrm{N}=611)\end{array}$ \\
\hline \multicolumn{3}{|l|}{ Race-no. (\%)† } \\
\hline White & $555(94.4)$ & $578(94.6)$ \\
\hline Black & $5(0.9)$ & $3(0.5)$ \\
\hline Asian & $2(0.3)$ & $0(0.0)$ \\
\hline Other & $26(4.4)$ & $30(4.9)$ \\
\hline \multicolumn{3}{|l|}{ Age } \\
\hline Median - yr & 66 & 66 \\
\hline Range $-y r$ & $50-85$ & $50-85$ \\
\hline \multicolumn{3}{|l|}{ Group - no. (\%) } \\
\hline$<65 \mathrm{yr}$ & $260(44.2)$ & $284(46.5)$ \\
\hline 65 to $<75 \mathrm{yr}$ & $226(38.4)$ & $213(34.9)$ \\
\hline$\geq 75 \mathrm{yr}$ & $102(17.3)$ & $114(18.7)$ \\
\hline \multicolumn{3}{|l|}{ Region - no. (\%) } \\
\hline Africa and Latin America & $107(18.2)$ & $107(17.5)$ \\
\hline Central and Eastern Europe & $151(25.7)$ & $161(26.4)$ \\
\hline Northern Europe & $101(17.2)$ & $112(18.3)$ \\
\hline Western and Southern Europe and Oceania & $229(38.9)$ & $231(37.8)$ \\
\hline \multicolumn{3}{|l|}{ Total testosteronetr } \\
\hline Mean - ng/dl & $451 \pm 145.9$ & $439 \pm 150.3$ \\
\hline$\leq 230$ ng/dl - no./total no. (\%) & $23 / 495(4.6)$ & $32 / 516(6.2)$ \\
\hline$>230-350 \mathrm{ng} / \mathrm{dl}-$ no./total no. (\%) & $93 / 495(18.8)$ & $117 / 516(22.7)$ \\
\hline$>350$ ng/dl — no./total no. (\%) & $379 / 495(76.6)$ & $367 / 516(71.1)$ \\
\hline Hypogonadism — no. (\%) & $2(0.3)$ & $1(0.2)$ \\
\hline \multicolumn{3}{|l|}{ Bone mineral density $T$ score $\mathbb{}$} \\
\hline Femoral neck & $-2.23 \pm 0.677$ & $-2.24 \pm 0.685$ \\
\hline Total hip & $-1.70 \pm 0.764$ & $-1.72 \pm 0.808$ \\
\hline \multicolumn{3}{|l|}{ Vertebral fractures — no. (\%) } \\
\hline 0 & $404(68.7)$ & $409(66.9)$ \\
\hline 1 & $114(19.4)$ & $135(22.1)$ \\
\hline$\geq 2$ & $69(11.7)$ & $66(10.8)$ \\
\hline $\begin{array}{c}\text { Osteoporosis medications used before the first } \\
\text { infusion in the study - no. (\%) }\end{array}$ & $11(1.9)$ & $8(1.3)$ \\
\hline Bisphosphonates & $8(1.4)$ & $7(1.1)$ \\
\hline Calcitonin & $4(0.7)$ & $1(0.2)$ \\
\hline
\end{tabular}

* Plus-minus values are means $\pm S D$. There were no significant differences between the groups. To convert values for total testosterone to nanomoles per liter, multiply by 0.0347 .

$\uparrow$ Race was self-reported.

7 Data are for all patients with baseline total testosterone measurements that were performed by noon.

$\int$ Data are for 586 patients in the zoledronic acid group and 608 patients in the placebo group who had baseline bone mineral density measurements.

I A patient who had received multiple medications within the same category was counted only once. One patient in the zoledronic acid group received both calcitonin and bisphosphonate therapies before the first infusion. according to serum levels of total testosterone, with the use of thresholds at $350 \mathrm{ng}$ per deciliter (12.1 nmol per liter) and $230 \mathrm{ng}$ per deciliter (8.0 nmol per liter) based on published recommendations for testosterone substitution, ${ }^{19}$ were performed with the use of the same model as that used for the overall analyses. Only participants with total testosterone measurements performed by noon were included in this analysis. The interference of the total testosterone level with the effect of zoledronic acid was evaluated with the use of an additional interaction term for study treatment and total testosterone level.

The study had $90 \%$ power to detect a $65 \%$ reduction in new morphometric vertebral fractures over the 24-month period at a two-sided $5 \%$ significance level, assuming a $7.7 \%$ incidence rate in the placebo group. The safety population included all participants who received one or more doses of the study drug.

\section{RESULTS}

\section{STUDY PARTICIPANTS}

In total, 588 men were randomly assigned to zoledronic acid, and 611 men were randomly assigned to placebo (Fig. 1); 58 men (9.9\%) and 71 men $(11.6 \%)$ in the two groups, respectively, discontinued the study. The modified intention-to-treat population comprised a total of 553 men who received zoledronic acid and 574 men who received placebo; these patients underwent baseline assessments and one or more post-baseline assessments of the primary efficacy variable. Fifty-two men who received zoledronic acid (8.8\%) and 53 men who received placebo $(8.7 \%)$ did not receive the second infusion.

Baseline characteristics were similar between the groups (Table 1). Total testosterone measurements were available for 495 participants who received zoledronic acid and 516 participants who received placebo. A total of 116 men who received zoledronic acid (23.4\%) and 149 men who received placebo $(28.9 \%)$ had a total testosterone level of 350 ng per deciliter or less; a small proportion of men in the two groups combined (5.4\%) had levels of $230 \mathrm{ng}$ per deciliter or less. Baseline bone mineral density and bone-turnover marker levels were similar across all subgroups of total testosterone levels (Table S1 in the Supplementary Appendix); results with the use of $230 \mathrm{ng}$ per deciliter as the threshold were similar to those 
with the use of $350 \mathrm{ng}$ per deciliter (Tables S2, S3, and S4 in the Supplementary Appendix).

\section{FRACTURES}

A total of 30 of 553 men in the zoledronic acid group (5.4\%) and 40 of 574 men in the placebo group (7.0\%) had radiographs that could be evaluated at month 12 but not at month 24; 4 men $(0.7 \%)$ and 3 men $(0.5 \%)$, respectively, had radiographs that could be evaluated at month 24 only; the remaining patients had radiographs that could be evaluated at both time points. A significantly lower proportion of men in the zoledronic acid group (1.6\%) had one or more new morphometric vertebral fractures over 24 months, as compared with men in the placebo group (4.9\%) (Fig. 2), corresponding to an absolute risk reduction of 3.3 percentage points and a relative risk reduction of $67 \%(\mathrm{P}=0.002)$. Sensitivity analyses with the use of data on patients for whom results of radiography at month 24 were available, single imputation, and multiple imputation had similar results (Table S5 in the Supplementary Appendix). A 68\% reduction in the relative risk of new morphometric vertebral fractures with zoledronic acid was apparent at month $12(\mathrm{P}=0.02)$ (Fig. 2, and Table S6A in the Supplementary Appendix). The total testosterone level did not affect the antifracture efficacy of zoledronic acid ( $\mathrm{P}>0.80$ for interaction). Among men with serum total testosterone levels of $350 \mathrm{ng}$ per deciliter or less, zoledronic acid was associated with a nonsignificant $67 \%$ reduction in the relative risk of new morphometric vertebral fractures $(\mathrm{P}=0.13)$ (Table S2 in the Supplementary Appendix).

Significantly fewer men who received zoledronic acid than men who received placebo had one or more new moderate-to-severe morphometric vertebral fractures, both at month 12 (relative risk reduction, $81 \% ; \mathrm{P}=0.01$ ) and at month 24 (relative risk reduction, 63\%; $\mathrm{P}=0.03$ ). Similar results were seen for new or worsening morphometric vertebral fractures at month 12 (relative risk reduction, 55\%; $\mathrm{P}=0.07$ ) and month 24 (relative risk reduction, $59 \% ; \mathrm{P}=0.007$ ). Changes in height (least-squares mean) from baseline were -0.8 and $-2.5 \mathrm{~mm}$ at month $12(\mathrm{P}=0.008)$ and -2.2 and $-4.5 \mathrm{~mm}$ at month $24(\mathrm{P}=0.002)$ in the zoledronic acid and placebo groups, respectively.

Six men who received zoledronic acid (1.0\%) and 11 men who received placebo (1.8\%) had one or more clinical vertebral or nonvertebral fractures during the study (Table S6B in the Supple-

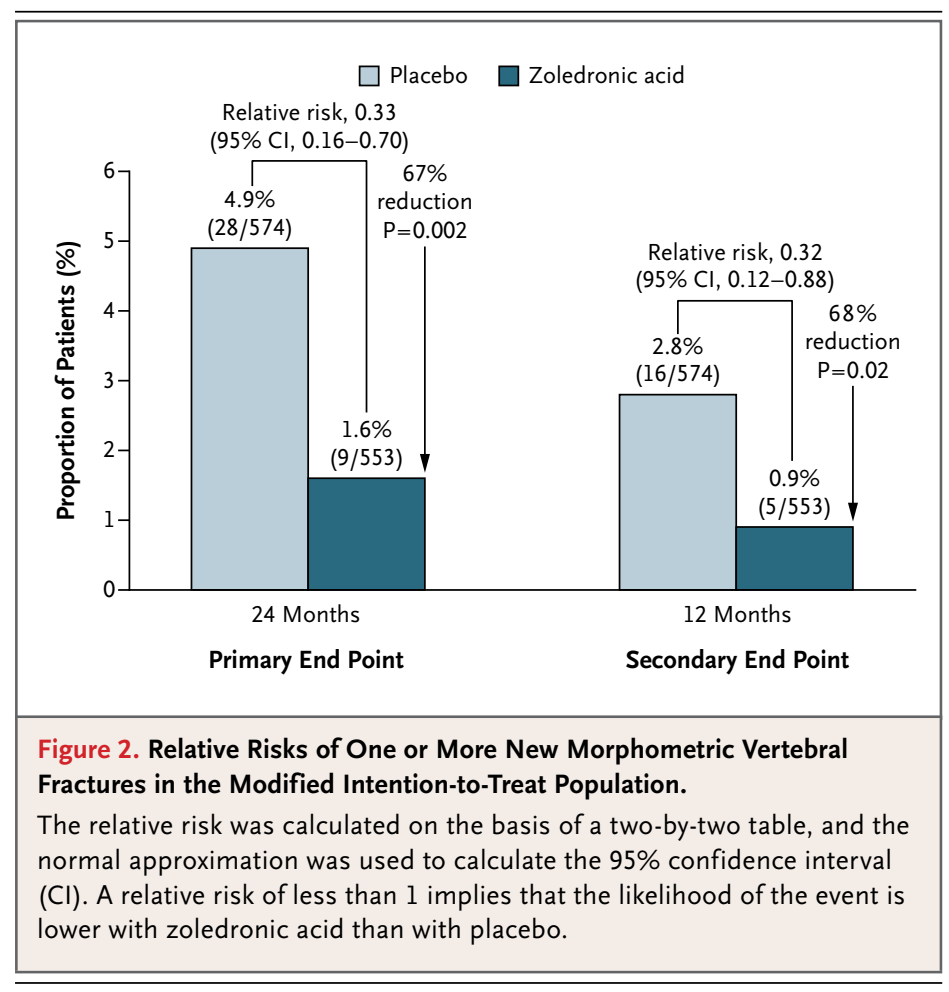

mentary Appendix), but the between-group difference was not significant. With the use of the observed effects in the HORIZON studies, ${ }^{13,14}$ Bayesian analyses suggested that zoledronic acid may reduce the risk of clinical fractures among men (Table S6C in the Supplementary Appendix).

\section{BONE DENSITY}

As compared with placebo, zoledronic acid was associated with significant and sustained increases in bone mineral density at the lumbar spine, total hip, and femoral neck over a 24-month period ( $\mathrm{P}<0.05$ for all comparisons) (Fig. 3, and Fig. S1A and S1B in the Supplementary Appendix). The effect of zoledronic acid on bone mineral density was similar in men with total testosterone levels of more than 350 ng per deciliter and in men with levels of $350 \mathrm{ng}$ per deciliter or less ( $\mathrm{P}>0.40$ for interaction) (Table $\mathrm{S} 3$ in the Supplementary Appendix).

\section{BIOCHEMICAL MARKERS}

Serum $\beta$-CTX, PINP, and BSAP levels were lower in men who received zoledronic acid than in men who received placebo at all time points measured ( $\mathrm{P}<0.001$ for all comparisons) (Fig. 3, and Fig. S1C in the Supplementary Appendix). A similar pat- 


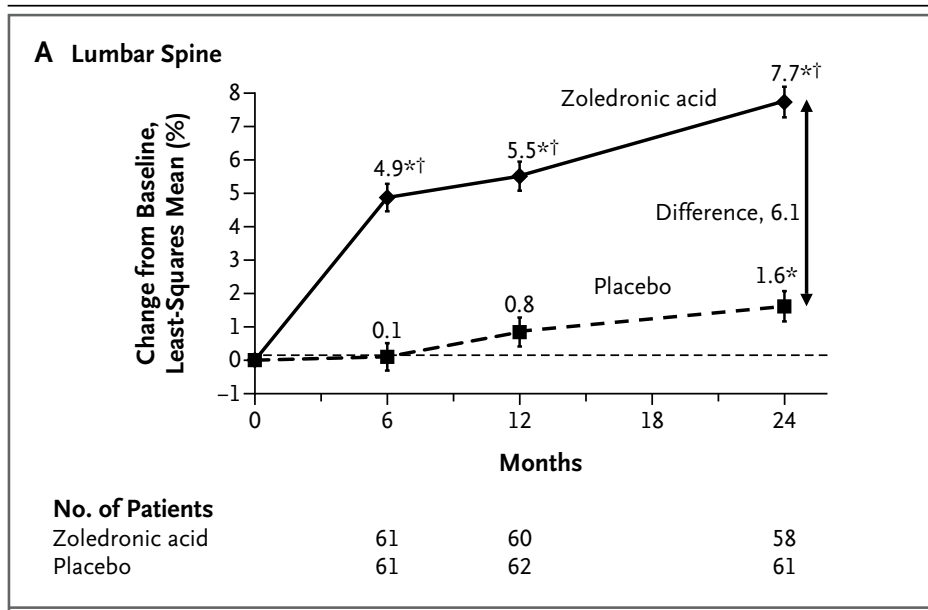

B Serum $\beta$-CTX

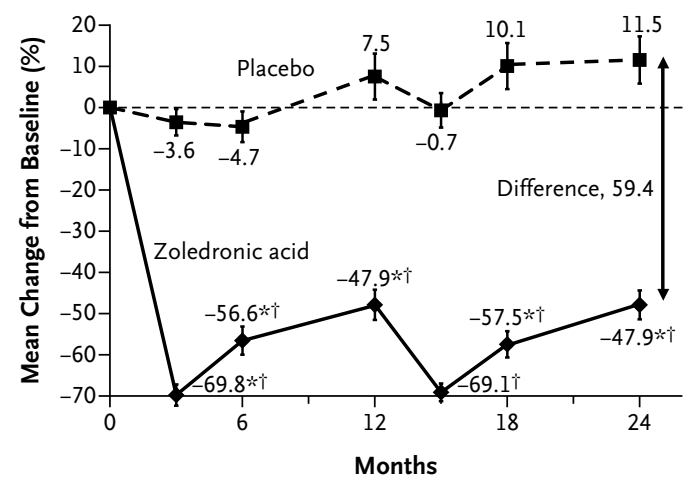

No. of Patients

Zoledronic acid

Placebo

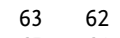

$63 \quad 55 \quad 55$

55

C Serum PINP

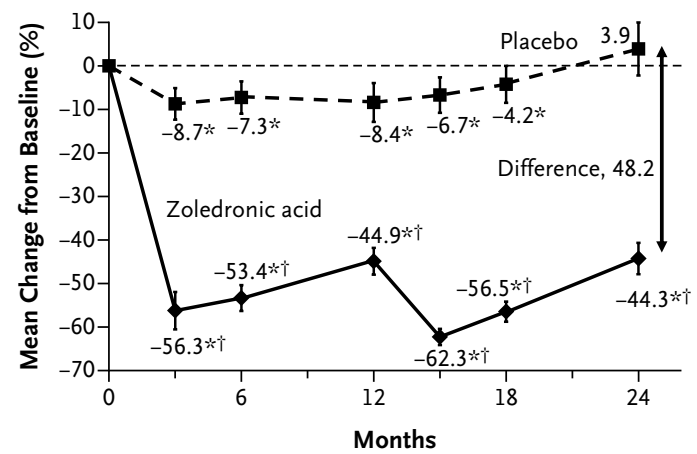

No. of Patients

Zoledronic acid

Placebo $\begin{array}{lll}63 & 56 & 56 \\ 64 & 58 & 60\end{array}$

58

62

tern was seen in urinary $\mathrm{N}$-terminal telopeptide levels ( $\mathrm{P}<0.001$ for all comparisons). The effect of zoledronic acid on bone-turnover markers was generally similar in men with total testosterone levels of more than $350 \mathrm{ng}$ per deciliter and those with levels of $350 \mathrm{ng}$ per deciliter or less $(\mathrm{P}>0.10$

Figure 3. Percentage Change in Bone Mineral Density and Biochemical Markers over Time.

Results are shown for bone mineral density at the lumbar spine (Panel A), serum $\beta$-C-terminal telopeptide of type 1 collagen $(\beta$-CTX) (Panel B), and procollagen type I $\mathrm{N}$-terminal propeptide (PINP) (Panel C) in a subgroup of patients. The asterisk denotes $\mathrm{P}<0.05$ for the comparison with the baseline value, and the single dagger $\mathrm{P}<0.001$ for the between-group comparison. Zoledronic acid or placebo was administered at months 0 and 12. The error bars represent standard errors of the mean. In Panels B and C, the values shown are based on unadjusted mean percentage changes.

for interaction at months 12 and 24) (Table S4 in the Supplementary Appendix), with the exception of PINP, for which the reduction was significantly less in the subgroup of men with total testosterone levels of $350 \mathrm{ng}$ per deciliter or less than in the subgroup with levels of more than $350 \mathrm{ng}$ per deciliter $(\mathrm{P}<0.02)$.

\section{SAFETY}

No significant differences were observed between the two groups with respect to deaths or serious adverse events, with the exception of any myocardial infarction (in nine men [1.5\%] in the zoledronic acid group and two [0.3\%] in the placebo group, $[\mathrm{P}=0.03]$; none of the events were considered by the investigator to be related to the study drug) (Table 2). There were 31 cardiac serious adverse events in the zoledronic group (5.3\%) and 30 in the placebo group (4.9\%) $(\mathrm{P}=0.79)$. Men who received zoledronic acid reported more adverse events of pyrexia, myalgia, arthralgia, headaches, chills, pain in the extremities, and influenza-like symptoms. There were no significant differences between the groups in the incidence of atrial fibrillation, cardiac arrhythmias, or renal dysfunction. No cases of osteonecrosis of the jaw were observed. Two men in the zoledronic acid group and one man in the placebo group had hip fractures during the study, but none were atypical or subtrochanteric.

\section{DISCUSSION}

Over a 2-year period, two annual infusions of zoledronic acid significantly reduced the risk of new morphometric vertebral fractures by $67 \%$ among men with osteoporosis. This reduction was similar to that reported in postmenopausal women with osteoporosis who received zoledronic acid (relative reduction in the risk of ver- 


\begin{tabular}{|c|c|c|c|}
\hline \multirow[t]{2}{*}{ Event } & $\begin{array}{l}\text { Zoledronic Acid } \\
\qquad(\mathrm{N}=588)\end{array}$ & $\begin{array}{l}\text { Placebo } \\
(\mathrm{N}=611)\end{array}$ & P Value' \\
\hline & \multicolumn{2}{|c|}{ no. of patients (\%) } & \\
\hline \multicolumn{4}{|l|}{ General } \\
\hline Any adverse event & $534(90.8)$ & $466(76.3)$ & $<0.001$ \\
\hline Any serious adverse event & $149(25.3)$ & $154(25.2)$ & \\
\hline Death & $15(2.6)$ & $18(2.9)$ & \\
\hline \multicolumn{4}{|l|}{ Five most common adverse events in zoledronic acid group } \\
\hline Pyrexia & $143(24.3)$ & $23(3.8)$ & $<0.001$ \\
\hline Myalgia & $129(21.9)$ & $25(4.1)$ & $<0.001$ \\
\hline Arthralgia & $123(20.9)$ & $68(11.1)$ & $<0.001$ \\
\hline Back pain & $84(14.3)$ & $74(12.1)$ & \\
\hline Headache & $82(13.9)$ & $27(4.4)$ & $<0.001$ \\
\hline \multicolumn{4}{|l|}{ Renal event } \\
\hline $\begin{array}{l}\text { Increase from baseline in serum creatinine }>0.5 \mathrm{mg} / \mathrm{dl} \\
\text { any time during study } \$\end{array}$ & $14(2.4)$ & $18(3.0)$ & \\
\hline Urinary protein on dipstick analysis, $>2+\mathbb{\Omega}$ & $1(0.2)$ & $1(0.2)$ & \\
\hline Creatinine clearance $<30 \mathrm{ml} / \mathrm{min}$ at any time during study 9 & $3(0.5)$ & $9(1.6)$ & \\
\hline \multicolumn{4}{|l|}{ Cardiac or cardiovascular event } \\
\hline \multicolumn{4}{|l|}{ Hypertension } \\
\hline Adverse event & $50(8.5)$ & $46(7.5)$ & \\
\hline Serious adverse event & $3(0.5)$ & $3(0.5)$ & \\
\hline Cardiac disorder, serious adverse event & $31(5.3)$ & $30(4.9)$ & \\
\hline Atrial fibrillation, serious adverse event & $7(1.2)$ & $5(0.8)$ & \\
\hline Angina pectoris, serious adverse event & $6(1.0)$ & $7(1.1)$ & \\
\hline \multicolumn{4}{|l|}{ Myocardial infarction } \\
\hline Any, serious adverse event & $9(1.5)$ & $2(0.3)$ & $<0.05$ \\
\hline Acute, serious adverse event & $5(0.9)$ & $1(0.2)$ & \\
\hline Serious adverse event & $4(0.7)$ & $1(0.2)$ & \\
\hline Cardiac failure, serious adverse event & $1(0.2)$ & $4(0.7)$ & \\
\hline
\end{tabular}

* A participant with multiple occurrences of an adverse event within a preferred term (according to codes used in the Medical Dictionary for Regulatory Activities) was counted only once.

$\uparrow P$ values are based on Fisher's exact test.

$\mp$ A total of 584 patients in the zoledronic acid group and 610 patients in the placebo group had serum creatinine measurements that could be evaluated at both baseline and one or more time points after the baseline visit.

$\int A$ total of 556 patients in the zoledronic acid group and 572 patients in the placebo group had urinary protein measurements that could be evaluated at both baseline and one or more time points after the baseline visit.

II A total of 557 patients in the zoledronic acid group and 577 patients in the placebo group had creatinine clearance measurements that could be evaluated at both baseline and one or more time points after the baseline visit. Creatinine clearance was calculated with the use of the Cockroft-Gault formula. ${ }^{16}$

tebral fracture, $71 \%$ at 2 years), ${ }^{13}$ suggesting that the antifracture effect of zoledronic acid is independent of sex. Zoledronic acid therapy had an acceptable safety profile. These results provide support for the value of antiresorptive therapy in men with osteoporosis.

Our study showed that zoledronic acid reduced the risk of height loss and moderate-to-severe vertebral fractures, which are associated with an increased risk of subsequent vertebral and nonvertebral fractures. ${ }^{20-23}$ Although the power of the study to detect a reduction in the risk of nonvertebral fracture was modest, rates of nonvertebral fracture were consistently lower among men who received zoledronic acid than among those who received placebo, and the point estimates were 
similar to the significant risk reductions in larger studies involving women. ${ }^{13}$

Zoledronic acid significantly improved bone mineral density and reduced bone-turnover markers, with changes from baseline that were similar to those reported for other bisphosphonates in men with osteoporosis ${ }^{6-9}$ and were consistent with those seen in postmenopausal women with osteoporosis receiving bisphosphonates (including zoledronic acid). ${ }^{13,24,25}$ Previous studies of bisphosphonates in men with osteoporosis have consistently revealed beneficial effects on bone mineral density and bone-turnover markers, but they were not primarily designed to assess the effects on fractures. ${ }^{6-9}$ For example, alendronate lowered the incidence of morphometric vertebral fractures (a secondary end point) in men in a 2-year doubleblind trial involving 241 patients, but the number of fractures was small.7 Since clinical data showing a reduction in the risk of fracture among men with osteoporosis have been lacking, our study was designed to be placebo-controlled. We believed that clinical equipoise existed and that a positive result would probably improve care for men with osteoporosis. Recently, denosumab was shown to reduce the risk of vertebral fracture (a secondary end point) among men receiving androgen-deprivation therapy for nonmetastatic prostate cancer. ${ }^{26,27}$ Our data provide further support for the precept that antiresorptive treatments are effective in both men and women.

In our study, zoledronic acid had similar beneficial effects on fractures and bone mineral density in men with low testosterone levels and men with normal levels. However, few men had total testosterone levels that were low enough $(<230 \mathrm{ng}$ per deciliter) to benefit from testosterone treatment, ${ }^{19}$ making it difficult to draw conclusions about the effect of zoledronic acid in this population. Furthermore, because the randomization was not stratified according to total testosterone level, the numbers of patients with low levels in the two groups were different.

Despite the fact that current public health efforts to detect osteoporosis and prevent fractures in men are inadequate, ${ }^{28}$ the ability to establish detection and treatment recommendations has been limited because of the absence of unambiguous evidence of effective antifracture therapies in men. ${ }^{11}$ Although our findings with zoledronic acid do not imply that all data on drugs for osteoporosis in women can be extrapolated to men, our study should provide the confidence to proceed.
A key strength of this study was a study population that was sufficiently large to detect an effect of treatment on the risk of vertebral fracture. However, the study was not powered to address the effect of zoledronic acid on nonvertebral (including hip) fractures. For ethical reasons, men with multiple or severe vertebral fractures were not enrolled, and the patient population was relatively young. The significant difference that we observed in the incidence of myocardial infarction between the groups has not previously been observed with zoledronic acid, ${ }^{13,14}$ and any causality or association with zoledronic acid is unknown.

In conclusion, our prospective study that assessed fractures as the primary end point in men with osteoporosis showed that over a 2-year period, a once-yearly infusion of zoledronic acid at a dose of $5 \mathrm{mg}$ was associated with a significant decrease in the risk of new vertebral fractures.

\section{Supported by Novartis Pharma.}

Dr. Antunez reports being an employee of and owning stock in Novartis. Dr. Boonen reports receiving payment to his institution, the University Hospitals Leuven, for serving on the board of Amgen, Novartis, and Servier; consulting fees from Amgen, Novartis, Servier, and Warner Chilcott; grant support from Novartis; and lecture fees and payment for travel accommodations from Amgen, Novartis, and Servier. Dr. Brixen reports serving on the board for Osteologix, Servier, Amgen, and Novartis and receiving payment for expert testimony on a patent for strontium maleate in the United States and consulting fees from Osteologix; lecture fees from Servier, Amgen, GlaxoSmithKline, and Novartis; and payment for travel accommodation from Amgen, Eli Lilly, Servier, and Novartis. Dr. Brixen reports receiving grant support to his institution, Odense University Hospital, from Merck Sharp \& Dohme and Novartis and investigator payments from Merck Sharp \& Dohme, Osteologix, Servier, Amgen, Natural Product Sciences Pharmaceuticals, and Eli Lilly. Dr. Bucci-Rechtweg reports being an employee of and owning stock in Novartis. Dr. Dimai reports serving on the board and receiving consulting fees and payment for travel accommodations from Novartis, Nycomed, Amgen, Eli Lilly, Merck Sharp \& Dohme, Servier, and Daiichi-Sankyo; lecture fees from Novartis, Nycomed, Amgen, Eli Lilly, Merck Sharp \& Dohme, Servier, Kyphon, and Daiichi-Sankyo; payment for manuscript preparation from Amgen and Servier; payment for development of educational presentations from Servier and Merck Sharp \& Dohme; and grant support to his institution, the Medical University of Graz, from Novartis, Nycomed, Amgen, Eli Lilly, Merck Sharp \& Dohme, Servier, and Kyphon. Dr. Eriksen reports receiving consulting fees from Eli Lilly and Amgen and lecture fees from Eli Lilly, Amgen, and Novartis. Dr. Hruska reports being an employee of Novartis. Ms. Incera reports being an employee of Novartis. Dr. Kaufman reports receiving consulting fees from Servier and payment for travel accommodations from Merck, Novo Nordisk, Eli Lilly, Novartis, and Servier. Dr. Kaufman reports receiving payment to his institution, Ghent University Hospital, for serving on the board of Servier; payment for expert testimony about teriparatide and consulting fees from Eli Lilly; and grant support from Novartis, Merck, Sanofi-Aventis, GlaxoSmithKline, Servier, Roche, Procter \& Gamble, Amgen, and Nycomed. Dr. Langdahl reports serving on the board for Novartis, Eli Lilly, Merck Sharp \& Dohme, Nycomed, and Amgen and receiving lecture fees from Eli Lilly, Merck Sharp \& Dohme, Amgen, GlaxoSmithKline, and Servier and grant support to his institution, the Aarhus Univer- 
sity Hospital, from Eli Lilly, Amgen, and Merck Sharp \& Dohme. Dr. Lippuner reports receiving consulting fees from Amgen, Daiichi-Sankyo, Eli Lilly, Merck Sharp \& Dohme, Nycomed, Pfizer, and Roche; lecture fees from Amgen and Daiichi-Sankyo; and grant support to his institution, University of Bern, from Amgen, Merck Sharp \& Dohme, Roche, and Servier. Dr. Lipschitz reports serving on the board for Novartis, Servier, and Merck Sharp \& Dohme; receiving consulting fees and payment for development of educational presentations from Servier; lecture fees from Merck Sharp \& Dohme, Servier, Novartis, and Eli Lilly; and payment for travel and accommodations from Merck Sharp \& Dohme and Servier. Dr. Orwoll reports receiving consulting fees from Amgen, Axon Advisors, Eli Lilly, GTx, Merck Sharp \& Dohme, RAND, and Wright Medical Technology; grants to his institution, Oregon Health and Science University, from Amgen, Eli Lilly, Merck Sharp \& Dohme, and O.N. Diagnostics; payment for expert testimony from the County of Placer, California, and the U.S. Department of Justice; and royalty payments from Springer and Academic Press (Elsevier). Dr. Papanastasiou reports being an employee of and owning stock in Novartis. Dr. Reginster reports receiving consulting fees from Servier, Novartis, Negma, Eli Lilly, Wyeth, Amgen, GlaxoSmithKline, Roche,
Merckle, Nycomed, Natural Product Sciences Pharmaceuticals, Theramex, and Union Chimique Belge; grants from Bristol-Myers Squibb, Merck Sharp \& Dohme, Rottapharm, Teva, Eli Lilly, Novartis, Roche, GlaxoSmithKline, Amgen, and Servier; and lecture fees from Merck Sharp \& Dohme, Eli Lilly, Rottapharm, Institut Biochimique, Genévrier, Novartis, Servier, Roche, GlaxoSmithKline, Teijin, Teva, Ebewe Pharma, Zodiac, Analis, Theramex, Nycomed, Novo Nordisk, and Nolver. Dr. Rizzoli reports serving on the board and receiving consulting and lecture fees from Novartis, Amgen, Servier, Eli Lilly, Danone, Nestlé, and Nycomed and grant support from Danone, Servier, and Novartis. Dr. Su reports being an employee of and owning stock in Novartis. Dr. Zanchetta reports serving on the board for Pfizer and receiving consulting fees from Eli Lilly, Merck Sharp \& Dohme, GlaxoSmithKline, and Servier and lecture fees from Eli Lilly.

Disclosure forms provided by the authors are available with the full text of this article at NEJM.org.

We thank the principal investigators of the study (a complete list of investigators is available in the Supplementary Appendix), Carrie Nielson, Ph.D., Oregon Health and Science University, for her independent statistical review of data for this trial, and the late Roger Boonen for his inspiration and support.
REFERENCES

1. Looker AC, Orwoll ES, Johnston CC Jr, et al. Prevalence of low femoral bone density in older U.S. adults from NHANES III. J Bone Miner Res 1997;12:1761-8.

2. Center JR, Nguyen TV, Schneider D, Sambrook PN, Eisman JA. Mortality after all major types of osteoporotic fracture in men and women: an observational study. Lancet 1999;353:878-82.

3. Johnell O, Kanis JA. An estimate of the worldwide prevalence and disability associated with osteoporotic fractures. Osteoporos Int 2006;17:1726-33.

4. Haentjens P, Magaziner J, Colón-Emeric $\mathrm{CS}$, et al. Meta-analysis: excess mortality after hip fracture among older women and men. Ann Intern Med 2010;152:380-90.

5. Orwoll ES, Scheele WH, Paul S, et al. The effect of teriparatide [human parathyroid hormone (1-34)] therapy on bone density in men with osteoporosis. J Bone Miner Res 2003;18:9-17.

6. Boonen S, Orwoll ES, Wenderoth D Stoner KJ, Eusebio R, Delmas PD. Onceweekly risedronate in men with osteoporo sis: results of a 2-year, placebo-controlled, double-blind, multicenter study. J Bone Miner Res 2009;24:719-25.

7. Orwoll $\mathrm{E}$, Ettinger $\mathrm{M}$, Weiss $\mathrm{S}$, et al Alendronate for the treatment of osteoporosis in men. N Engl J Med 2000;343:604-10. 8. Orwoll ES, Miller PD, Adachi JD, et al. Efficacy and safety of a once-yearly i.v. infusion of zoledronic acid $5 \mathrm{mg}$ versus a once-weekly $70-\mathrm{mg}$ oral alendronate in the treatment of male osteoporosis: a randomized, multicenter, double-blind, activecontrolled study. J Bone Miner Res 2010 25:2239-50.

9. Orwoll ES, Binkley NC, Lewiecki EM, Gruntmanis U, Fries MA, Dasic G. Efficacy and safety of monthly ibandronate in men with low bone density. Bone 2010;46: 970-6.

10. Frost M, Wraae K, Abrahamsen B, et al. Osteoporosis and vertebral fractures in men aged 60-74 years. Age Ageing 2012; 41:171-7.

11. Screening for osteoporosis: U.S. Preventive Services Task Force recommendation statement. Ann Intern Med 2011;154: 356-64.

12. Feldstein AC, Nichols G, Orwoll E, et al. The near absence of osteoporosis treatment in older men with fractures. Osteoporos Int 2005;16:953-62.

13. Black DM, Delmas PD, Eastell R, et al. Once-yearly zoledronic acid for treatment of postmenopausal osteoporosis. N Engl J Med 2007;356:1809-22.

14. Lyles KW, Colón-Emeric CS, Magaziner JS, et al. Zoledronic acid and clinical fractures and mortality after hip fracture. N Engl J Med 2007;357:1799-809.

15. Genant HK, Wu CY, van Kuijk C, Nevitt MC. Vertebral fracture assessment using a semiquantitative technique. J Bone Miner Res 1993;8:1137-48.

16. Cockcroft DW, Gault MH. Prediction of creatinine clearance from serum creatinine. Nephron 1976;16:31-41.

17. World Medical Association. Declaration of Helsinki: ethical principles for medical research involving human subjects. Tokyo: 55th WMA General Assembly, 2004 (http:// www.wma.net/en/30publications/

10policies/b3/index.html).

18. Neuenschwander B, Capkun-Niggli G, Branson M, Spiegelhalter DJ. Summarizing historical information on controls in clinical trials. Clin Trials 2010;7:5-18. 19. Wang C, Nieschlag E, Swerdloff R, et al. Investigation, treatment and monitoring of late-onset hypogonadism in males: ISA, ISSAM, EAU, EAA and ASA recommendations. Eur J Endocrinol 2008;159: 507-14.

20. Black DM, Arden NK, Palermo L, Pearson J, Cummings SR. Prevalent vertebral deformities predict hip fractures and new vertebral deformities but not wrist fractures. J Bone Miner Res 1999;14:821-8. 21. Delmas PD, Genant HK, Crans GG, et al. Severity of prevalent vertebral fractures and the risk of subsequent vertebral and nonvertebral fractures: results from the MORE trial. Bone 2003;33:522-32.

22. Lunt M, O'Neill TW, Felsenberg D, et al. Characteristics of a prevalent vertebral deformity predict subsequent vertebral fracture: results from the European Prospective Osteoporosis Study (EPOS). Bone 2003;33:505-13.

23. Puisto V, Heliovaara M, Impivaara $O$, et al. Severity of vertebral fracture and risk of hip fracture: a nested case-control study. Osteoporos Int 2011;22:63-8.

24. Reginster J, Minne HW, Sorensen $\mathrm{OH}$, et al. Randomized trial of the effects of risedronate on vertebral fractures in women with established postmenopausal osteoporosis. Osteoporos Int 2000;11:83-91. 25. Liberman UA, Weiss SR, Bröll J, et al. Effect of oral alendronate on bone mineral density and the incidence of fractures in postmenopausal osteoporosis. N Engl J Med 1995;333:1437-43.

26. Smith MR, Egerdie B, Hernández Toriz $\mathrm{N}$, et al. Denosumab in men receiving androgen-deprivation therapy for prostate cancer. N Engl J Med 2009;361:745-55.

27. Cummings SR, San Martin J, McClung MR, et al. Denosumab for prevention of fractures in postmenopausal women with osteoporosis. N Engl J Med 2009;361:756-65. [Erratum, N Engl J Med 2009;361:1914.]

28. Roerholt C, Eiken P, Abrahamsen B. Initiation of anti-osteoporotic therapy in patients with recent fractures: a nationwide analysis of prescription rates and persistence. Osteoporos Int 2009;20:299307.

Copyright (C) 2012 Massachusetts Medical Society. 